\title{
Análise da Vulnerabilidade Ambiental da Bacia Hidrográfica do Rio Claro (GO) Utilizando Geotecnologias
}

\author{
Analysis of Environmental Vulnerability of the Rio Claro \\ Hydrographic Basin (GO) Using Geotechnologies
}

\author{
Patrícia Tinoco Santos ${ }^{1}$, Alécio Perini Martins ${ }^{2}$ \\ 1Universidade Federal de Goiás, alecioperini@yahoo.com.br \\ Universidade Federal de Goiás, patriciatinoco91@gmail.com
}

Recebido (Received): 20/02/2018

Aceito (Accepted): 11/08/2018

\begin{abstract}
Resumo: A Bacia Hidrográfica do Rio Claro (BHRC) apresenta grande importância para a mesorregião Sul Goiano (GO), considerando que por meio da distribuição e correlação espacial dos elementos que formam o sistema da referida bacia dependem a economia, a sobrevivência e o bem-estar da população atual e das gerações futuras. O uso da terra para fins agropecuários $(78,2 \%)$, bem como sua caracterização quanto a geologia, geomorfologia, solos e clima, demonstra o grande potencial da região para tais atividades, entretanto, tal uso vem gerando degradação da área devido a práticas inadequadas de manejo. Os solos na área da BHRC possuem alta estabilidade, e o clima tropical, o qual apresenta elevada temperatura durante todo o ano e baixa amplitude térmica, garante médias elevadas de precipitação. A precipitação garante o abastecimento dos canais fluviais, entretanto, também favorecem erosões em áreas descobertas por vegetação. A partir de geotecnologias, e considerando a análise sistêmica da região, foi realizado o estudo da vulnerabilidade ambiental na área da BHRC, conforme metodologia de Crepani (2001), no qual se pode caracterizá-la como sendo de estabilidade intermediária, tendenciada a vulnerável (44,1\%). Foram detectadas em campo vulnerabilidade maiores do que a que foi apresentada nos resultados dos mapas, isso se deve pela baixa vulnerabilidade obtida em alguns temas como o clima e geomorfologia. As áreas mais vulneráveis encontram-se próximas as principais nascentes da bacia, e indicam a necessidade de intensificação de ações de conservação nessas áreas e a efetivação de políticas específicas para controle e monitoramento ambiental.
\end{abstract}

Palavras-chave: Degradação, Estabilidade, Conservação, Monitoramento.

Abstract: The Hydrographic Basin of the Rio Claro (BHRC) provides great importance for the mesoregion Sul Goiano (GO) considering that through distribution and spatial correlation of the elements that form the system of the previously mentioned basin, are depending the economy, the survival and the wellbeing of the current population and of future generations. The usage of land for farming purposes (78,2\%), as well as its characterization as to its geology, geomorphology, soil and climate demonstrates the big potential of the region for such activities, however, such usage has been generating degradation of the area because of inadequate management practices. The soils in the BHRC area have high stability, and the tropical climate, which presents elevated temperature all year long and low thermal amplitude, ensures high average rates of precipitation. Precipitation ensures the supply of the river channels, however, it also favors erosions in areas not covered by vegetation. From geotechnologies, and considering the systemic analysis of the region, it has been performed the study of the environmental vulnerability in the area of the BHRC, according methodology of Crepani (2001), in which it has been possible to characterize it as being of average stability, with tendency to vulnerable $(44,1 \%)$. In the field, it has been detected bigger vulnerabilities than the one that has been presented in the results from the maps; this is due to the low vulnerability obtained in some themes, like climate and geomorphology. The most vulnerable areas are located near the main water springs of the basin, and indicate the necessity of intensification of conservation actions in these areas and the effectiveness of specific politics for control and environmental monitoring.

Keywords: Degradation, Stability, Conservation, Monitoring. 


\section{Introdução}

No Brasil, o conceito legal de meio ambiente encontra-se descrito no art. $3^{\circ}$, Inciso I, da Lei $\mathrm{n}^{\circ} .6 .938 / 81$, o qual dispõe sobre a Política Nacional do Meio Ambiente, e diz que o meio ambiente é "o conjunto de condições, leis, influências e interações de ordem física, química e biológica, que permite, abriga e rege a vida em todas as suas formas". Sendo assim, pode-se inferir que tal conjunto é composto por condições que sustentam relações de dependência e troca dos seres vivos com o espaço. Os elementos que compõe o meio trocam matéria e energia, de modo que sua organização, o espaço e o tempo podem ser compreendidos como agentes condicionantes para isso.

A Teoria Geral dos Sistemas consiste em uma visão holística na qual o ambiente é concebido de forma integrada. Nesta perspectiva, é impossível a compreensão separada do mesmo. A água, o ar, o solo, os seres vivos, o juízo de valor sobre os atributos do meio, formas de uso e funções requerem uma análise integrada e integral, de modo a se compreender sua organização e complexidade em um sistema.

Sales (2004) avalia que a aplicação de tal teoria teve destaque nos Estados Unidos nas primeiras décadas do século XX, em consonância com o avanço da cibernética, devido ao trabalho pioneiro de Bertalanfy, em 1950, o qual definiu os sistemas como conjuntos de elementos que se relacionam entre si, com certo grau de organização, procurando atingir um objetivo ou uma finalidade. Na Geografia, a aplicação da visão sistêmica teve grandes contribuições de autores como Lefebvre (1974) apud MOREIRA 2014 para os embasamentos filosóficos e Santos (1985) na análise de sistemas de objetos e sistemas de ações. Também se pode citar as obras clássicas de Bertrand (1972), Tricart (1977), e Sotchava (1977, 1978, apud RODRIGUES 2001), os quais também falam sobre este tema.

Nesta perspectiva, o estudo de Bacias Hidrográficas se faz coerente enquanto categoria de análise sistêmica, no qual, nesta abordagem, em meio ao espaço, ao todo, dá-se ênfase ao meio ecológico, o que necessariamente, não quer dizer o detrimento de relevância dos estudos dos espaços geoconstruídos, mas simplesmente um recorte para aprofundamento de estudos sobre tal elemento. Tal abordagem caracteriza, assim, aspectos relevantes como paisagem e análise espacial.

Existem vários autores que trabalham questões da análise sistêmica em bacias hidrográficas. Campos (2006) considera as bacias hidrográficas como sistemas físicos e dinâmicos, Botelho e Silva (2012) tratam da evolução do uso da bacia hidrográfica como célula natural de análise, e pelo entendimento da visão geossistêmica na análise ambiental proposta por Rodrigues, Silva e Cavalcante (2017), é possível se justificar as noções de totalidade em bacias hidrográficas. As geotecnologias são ferramentas indispensáveis para análise e gestão em bacias hidrográficas, conforme Novo (2008) e Silva (2012), e seu desenvolvimento muito se deve a aplicação da Geografia Quantitativa aliada aos sistemas computacionais voltados para a análise espacial georreferenciada.

A Bacia do Rio Paranaíba, apresenta um comportamento que reflete as influências de um conjunto de condicionantes, tais como as condições morfoestruturais, tipos de solos, cobertura vegetal e clima. É uma área drenada por um conjunto de rios delimitados topograficamente, logo, pode ser considerada um sistema ou geossistema. Em escala maior, a BHRC compõe a referida bacia sedimentar, porém, a topografia delimita drenagens com condições mais específicas da mesorregião sul goiano, dessa forma, pode ser considerada um subsistema.

De acordo com a Secretaria do Meio Ambiente, dos Recursos Hídricos, Infraestrutura, Cidades e Assuntos Metropolitanos do Estado de Goiás - SECIMA (2016), a BHRC é intensamente antropizada e apresenta considerável degradação ambiental e poluição devido a dejetos de origem urbana, efluentes de indústrias e agroindústrias e pelo mau uso do solo e supressão da vegetação original. Isso também se dá devido à ocupação para agropecuária, o que para mesorregião sul goiano é muito expressivo.

Da distribuição e correlação espacial dos elementos que formam o sistema da área em análise dependem o bioma, a economia, a sobrevivência e o bem-estar da população local atual e das gerações futuras. Dada a importância da BHRC para a mesorregião sul do estado de Goiás, tal pesquisa tem por objetivo analisar de forma sistêmica o espaço, a partir dos aspectos de paisagem e análise espacial, bem como aplicar técnicas de geoprocessamento para delimitação e quantificação do espaço preexistente e das características globais, estes, imprescindíveis à explicação da estrutura, comportamento e bom funcionamento de tal sistema. 


\section{Materiais e método}

\section{1 Área de estudo}

A BHRC tem uma área de $13.611,00 \mathrm{~km}^{2}$, e está situada na mesorregião Sul Goiano entre os municípios de Caiapônia, Mineiros, Perolândia, Jataí, Rio Verde, Aparecida do Rio Doce, Caçu, Cachoeira Alta, Paranaiguara e São Simão, conforme Figura 1. A região está inserida na Região Hidrográfica do Paraná e faz parte da unidade de gestão hídrica da bacia do rio Paranaíba denominada Claro, Verde, Corrente e Aporé (ANA, 2015), e tem como principais drenagens o Rio Claro e o Rio Doce. Os canais fluviais que compõem a bacia são de fundamental importância para a manutenção do volume de água dos rios que os recebem, podese citar como exemplos o Ribeirão Bonfim, o Ribeirão Ariranha e o Ribeirão Paraíso (Figura 2).

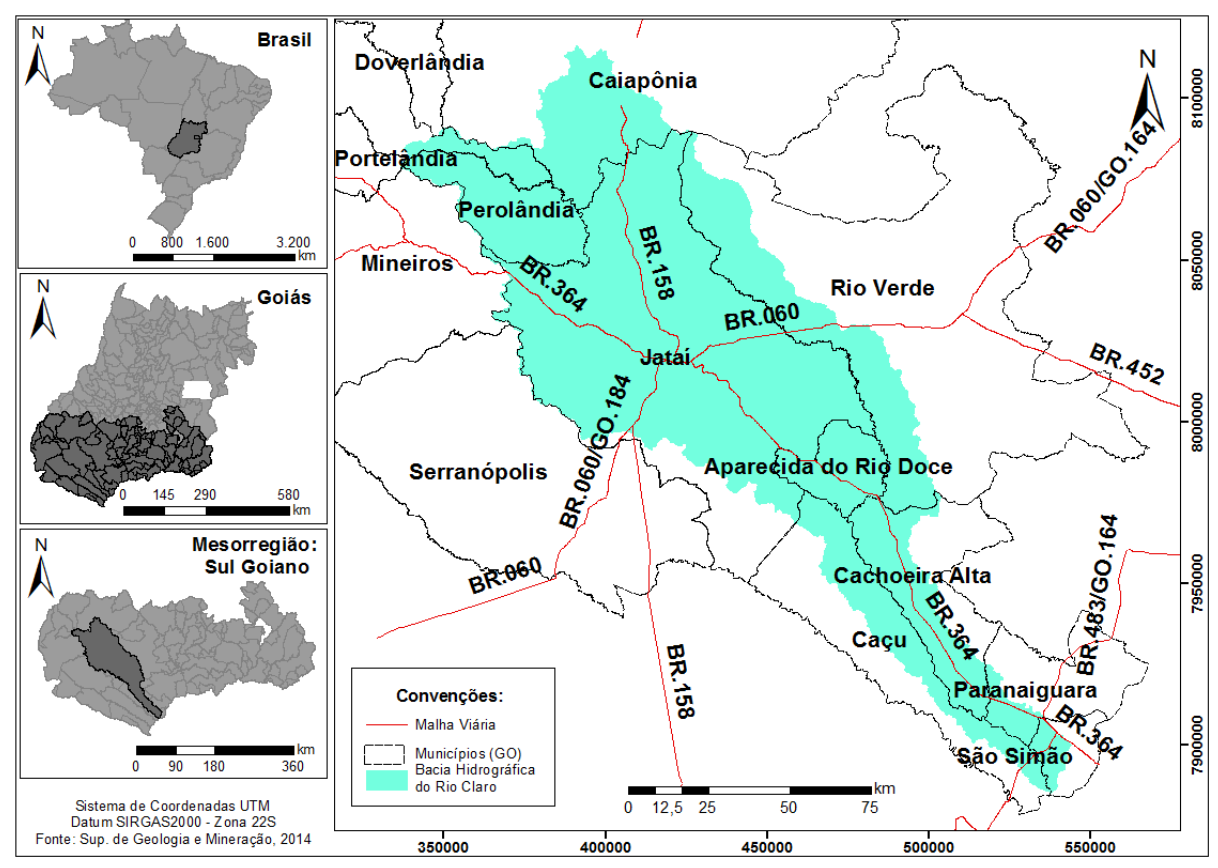

Figura 1: Localização da Bacia Hidrográfica do Rio Claro na mesorregião Sul Goiano - Goiás -Brasil. Fonte: SIEG, 2016.

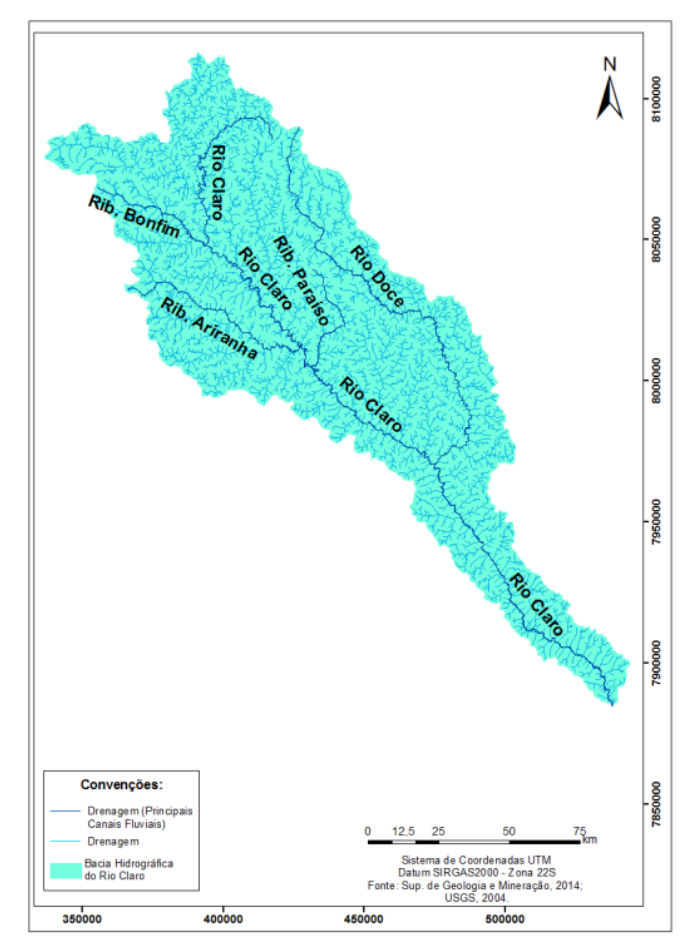

Figura 2: Rede hidrográfica da Bacia do Rio Claro na mesorregião Sul Goiano - Goiás - Brasil. 
Localizada no centro do Brasil, suas principais conexões inter-regionais se dão por meio de ligações predominantemente rodoviárias, sendo as principais a BR-060, BR-364 e BR-158. Próximo a Foz, no município de São Simão, têm-se o planejamento da construção de um trecho da ferrovia Norte-Sul. A acessibilidade à bacia também pode se dá pela ligação hidroviária do rio Paranaíba ao rio Paraná, a qual, a jusante, passa pelos estados de Minas Gerais, Mato Grosso do Sul e São Paulo, e segue pela região Sul do Brasil em direção ao Paraguai, Argentina e Uruguai. Desse modo, a localização da BHRC pode ser considerada estratégica dado que favorece o escoamento da produção agropecuária, principal atividade econômica da região.

\subsection{Procedimentos}

A elaboração da pesquisa primeiramente se constituiu em uma revisão bibliográfica da qual foram retirados os conceitos e métodos empregados nas análises. Foram utilizadas ferramentas e técnicas de geoprocessamento na elaboração das atividades de identificação, espacialização e caracterização da área da bacia.

A BHRC foi caracterizada a partir de sua análise fisiográfica e escala de vulnerabilidade. Para a análise de vulnerabilidade ambiental, foram ressaltados os temas referentes à Geologia, Geomorfologia, Solos, Clima e Uso da Terra e Cobertura Vegetal, como pode ser observado no Quadro 1, utilizando-se a metodologia de mapeamento da vulnerabilidade de paisagem à perda de solo desenvolvida por Crepani et al. (1996) e fundamentada no conceito de Ecodinâmica de Tricart (1977), cujo objetivo era de, por meio das potencialidades das imagens de satélite, subsidiar o Zoneamento Ecológico-Econômico.

Quadro 1: Características analisadas para avaliar a vulnerabilidade à perda de solo das unidades de Paisagem.

\begin{tabular}{cl}
\hline Temas & \multicolumn{1}{c}{ Características } \\
\hline Geologia & História da evolução Geológica \\
& Grau de coesão da rocha \\
& Amplitude altimétrica \\
Geomorfologia & Grau de dissecação (amplitude interfluvial) \\
& Declividade \\
Pedologia & Maturidade do solo \\
Vegetação / Uso da terra & Densidade da cobertura vegetal / Tipo de uso \\
Clima & Intensidade pluviométrica (pluviosidade anual / duração do período chuvoso) \\
\hline
\end{tabular}

Fonte: Crepani et al. (2001)

Crepani et al. (2001) apresenta que à Equação 1 são aplicados os temas geologia, geomorfologia, solos, vegetação/uso da terra e clima, os quais compõem uma unidade de paisagem, e representa, empiricamente, a posição da unidade de paisagem (ou Unidade Territorial Básica - UTB) na escala de vulnerabilidade à perda de solo. São atribuídos valores de vulnerabilidade que variam de 1,0 a 3,0 (sendo o 1,0 de maior estabilidade, o 2,0 de estabilidade intermediária e o 3,0 de maior vulnerabilidade) para cada classe de cada tema da fórmula $2 \mathrm{em}$ todos os Mapas temáticos. A partir daí, via álgebra de Mapas em SIG, é gerado o Mapa de vulnerabilidade à perda de solo das unidades de paisagem no qual o valor resultante é dado pela média aritmética dos valores individuais de cada tema.

$$
\mathrm{V}=\frac{\mathrm{G}+\mathrm{R}+\mathrm{S}+\mathrm{Vg}+\mathrm{C}}{5} \quad \text { Equação (1) }
$$

Em que:

$\mathrm{V}=$ Vulnerabilidade da unidade de paisagem; $\mathrm{G}=$ Vulnerabilidade para o tema Geologia; $\mathrm{R}=$ Vulnerabilidade para o tema Geomorfologia; $\mathrm{S}=$ Vulnerabilidade para o tema Solos; $\mathrm{Vg}=$ Vulnerabilidade para o tema Vegetação/Uso da terra; $\mathrm{C}=$ Vulnerabilidade para o tema Clima.

A avaliação do modelo, de forma relativa e empírica, do estágio de evolução morfodinâmica da unidade de paisagem (U), se dá pelas categorias Estável, Intermediária e Instável (Quadro 2). Para a representação cartográfica dos Mapas de vulnerabilidade, são atribuídas 21 cores (U) obtidas pela 
combinação das cores azul (maior estabilidade), verde (associada a estabilidade intermediária) e vermelho (associada a maior vulnerabilidade) (Quadro 3).

Quadro 2: Avaliação da estabilidade das categorias morfológicas.

\begin{tabular}{ccc}
\hline $\begin{array}{c}\text { Categoria } \\
\text { Morfodinâmica }\end{array}$ & $\begin{array}{c}\text { Relação Pedogênese/ } \\
\text { Morfogênese }\end{array}$ & Valor \\
\hline Estável & Prevalece a pedogênese & 1,0 \\
Intermediária & Equilíbrio pedogênese/ & 2,0 \\
Instável & Prevalece a morfogênese & 3,0 \\
\hline
\end{tabular}

Fonte: Crepani et al. (1996).

Quadro 3: Escala de Amplitude á Perda de Solo nas Unidades de Paisagem.

\begin{tabular}{|c|c|c|c|c|c|}
\hline $\begin{array}{l}\text { Unidade de } \\
\text { Paisagem }\end{array}$ & Média & Cores & $\begin{array}{l}\text { Unidade de } \\
\text { Paisagem }\end{array}$ & Média & Cores \\
\hline U1 & 3,0 & & U12 & 1,9 & \\
\hline $\mathrm{U} 2$ & 2,9 & & U13 & 1,8 & \\
\hline U3 & 2,8 & & U14 & 1,7 & \\
\hline $\mathrm{U} 4$ & 2,7 & & U15 & 1,6 & \\
\hline U5 & 2,6 & & U16 & 1,5 & \\
\hline U6 & 2,5 & & U17 & 1,4 & \\
\hline U7 & 2,4 & & U18 & 1,3 & \\
\hline U8 & 2,3 & & U19 & 1,2 & \\
\hline U9 & 2,2 & & $\mathrm{U} 20$ & 1,1 & \\
\hline U10 & 2,1 & & $\mathrm{U} 21$ & 1,0 & \\
\hline U11 & 2,0 & & & & \\
\hline
\end{tabular}

Fonte: Adaptado de Crepani et al. (1996).

A aplicação da metodologia de Crepani et al. (2001) na área da BHRC foi adaptada, de modo que não foram confeccionados os mapas que representassem os aspectos de amplitude altimétrica nem interfluvial, dado que tais fatores são pouco representativos em áreas extensas como a da bacia em análise.

Os dados de precipitação foram coletados do Instituto Nacional de Geografia e Estatística (INMET) e da Agência Nacional das Águas (ANA) e usados na interpolação Inverse Distance Weighting (IDW) para a confecção do mapa de vulnerabilidade do tema clima.

Também foram utilizados dados oficiais disponibilizados pela Secretaria de Planejamento do Estado através do Sistema Estadual de Geoinformação de Goiás (SIEG), Instituto Brasileiro de Geografia e Estatística (IBGE) e os vetores do macrozoneamento agroecológico e econômico de Goiás (ZAEE-GO).

Para o tema Vegetação/Uso da terra, o mapeamento da área foi feito por meio de imagens do satélite Landsat 8, sensor Operational Land Imager (OLI), do satélite Landsat 8. Tais imagens foram classificadas pelo método não-supervisionado e pós classificadas por interpretação visual.

Os meses da tomada das cenas utilizadas nessa análise variaram entre maio e julho devido a esses representarem um período seco no qual se podem obter imagens sem a presença de nuvens. As órbitas e pontos das cenas utilizadas para o recobrimento da BHRC foram: 222/073, 223/072, 223/073 e 224/072.

Para a validação do Mapa de cobertura vegetal e uso do solo no ano de 2016, foram realizadas quatro visitas a campo, nos dias 31/01/2017, 07/03/2017, 23/05/2017 e 13/06/2017, e coletados 109 pontos de 
controle. Pelo método estatístico do Coeficiente Kappa de Cohen (COEHN, 1960), verificou-se o nível de confiabilidade dos dados como sendo de $87 \%$, ou seja, excelente.

\section{Resultados e Discussões}

Para o tema Geologia, puderam-se caracterizar onze formações geológicas na BHRC, sendo: 9,1\% Aquidauana (1234,8 km2), 0,1\% Coberturas detrítico-lateríticas ferruginosas (14,9 km2), 2,0\% Corumbataí $\left(272,4 \mathrm{~km}^{2}\right), 1,8 \%$ Depósitos aluvionares $\left(247,5 \mathrm{~km}^{2}\right), 1,2 \%$ Irati $\left(161,5 \mathrm{~km}^{2}\right), 2,5 \%$ Marília $\left(339,5 \mathrm{~km}^{2}\right)$, 14,5\% Cachoeirinha $\left(1969,0 \mathrm{~km}^{2}\right), 10,6 \%$ Coberturas detríticas indiferenciadas $\left(1444,1 \mathrm{~km}^{2}\right), 4,9 \%$ Botucatu $\left(666,3 \mathrm{~km}^{2}\right), 18,3 \%$ Serra Geral $\left(2495,3 \mathrm{~km}^{2}\right)$ e $35,0 \%$ Vale do Rio do Peixe $\left(4765,7 \mathrm{~km}^{2}\right)$. Destacam-se os cinco últimos por estarem sob solos que representam os mais relevantes usos da região (agricultura e pastagem).

As formações Aquidauana, Botucatu, Corumbataí, Irati, e Marília originam solos com texturas arenosas e média arenosa e por isso costumam ser encontradas em áreas de pastagem ou remanescentes de vegetação nativa, enquanto que nas áreas com formações Cachoeirinha, Serra Geral, Coberturas Detrito-Lateríticas Ferruginosas e Detríticas indiferenciadas, costumam ser recobertos por áreas agrícolas. Grande parte da Vale do Rio do Peixe, mesmo com solos arenosos, é recoberta por agricultura. (Martins et al., 2016).

Observou-se que a BHRC é constituída por rochas sedimentares inorgânicas. Tais rochas, com suas respectivas proporções, podem ser vistas na Tabela 1.

Tabela 1: Escala de Vulnerabilidade à denudação das rochas mais comuns para a Bacia Hidrográfica do Rio Claro.

\begin{tabular}{cccc}
\hline ROCHAS & $\begin{array}{c}\text { Área } \\
\mathbf{K m}^{\mathbf{2}}\end{array}$ & $\begin{array}{c}\text { Porcentagem } \\
\mathbf{( \% )}\end{array}$ & Vuln. \\
\hline Aglomerado, Laterita, Argila, Areia & 14,9 & 0,1 & 3,0 \\
Arenito & 1005,8 & 7,4 & 2,4 \\
Arenito, Argilito arenoso & 4766,4 & 35,1 & 2,4 \\
Arenito, Siltito & 272,4 & 2,0 & 2,4 \\
Argilito, Arenito, Depósitos de areia & 1969,0 & 14,5 & 2,7 \\
Basalto, Basalto-andesito & 2495,3 & 18,4 & 1,5 \\
Depósitos de areia, Depósitos de cascalho & 247,5 & 1,8 & 3,0 \\
Depósitos de areia, Depósitos de cascalho, & 1444,1 & 10,6 & 3,0 \\
Depósitos de argila & 1190,1 & 8,8 & 2,4 \\
Diamictito, Folhelho, Arenito, Siltito & 161,5 & 1,2 & 2,8 \\
Folhelho & 44,0 & - & - \\
Massa d'água & 13611,0 & 100 & - \\
\hline
\end{tabular}

Fonte: Crepani et al. (1996). Adaptado pelos autores.

Dada à vulnerabilidade da geologia, observa-se que o grau de vulnerabilidade mais elevado pode ser observado nas áreas de nascentes das principais drenagens da BHRC. As Figuras 3 e 4 ilustram exemplos de formações rochosas observadas em campo. O sistema geomorfológico da BHRC é classificado conforme seu critério funcional, como não-isolado e aberto, ou seja, mantêm relações com os demais sistemas do universo o qual está inserido e mantêm constantes trocas (recebendo ou perdendo) de energia e matéria. (CRISTOFOLETTI, 1980, p.3). Para o tema Geomorfologia observou-se que a área que compreende a BHRC se situa em terras de mediana altitude (600 a 1100m), denominada Planalto Brasileiro.

A área estudada apresenta $0,3 \%(30,7 \mathrm{~km} 2)$ de áreas classificadas como de maior vulnerabilidade (considerando a escala de Vuln. entre 3,0 e 2,5) e se concentram mais nos interflúvios das principais drenagens da bacia e nas áreas de serras, conforme Figuras 5 e 6.

Apresenta $0,4 \%\left(55,1 \mathrm{~km}^{2}\right)$ de áreas de estabilidade intermediária, tendenciadas a vulnerável (considerando a escala de Vuln. entre 2,4 e 2,1), 2,4\% $\left(315,9 \mathrm{~km}^{2}\right)$ de áreas de estabilidade intermediária, tendenciadas a estável (considerando a escala de Vuln. entre 2,0 e 1,6), e 96,9\% $\left(13209,3 \mathrm{~km}^{2}\right)$ de áreas de maior estabilidade (considerando a escala de Vuln. entre 1,5 e 1,0).

O fato de o terreno apresentar $86,2 \%$ de área com declividade de até 8,2\% facilita a ocupação antrópica dessas áreas e a difusão da agricultura extensiva e monoculturas, isso se justifica devido à possibilidade de mecanização das lavouras e o acesso às fontes hídricas. Historicamente, a partir da década de 1960 e, sobretudo ao longo da década de 1970, extensas áreas dos interflúvios passaram a ser utilizadas para 
agricultura comercial, atualmente, frente a grande extensão das plantações de soja, tem-se o grande desafio da preservação dos patrimônios biológicos do cerrado nas áreas de bacias.

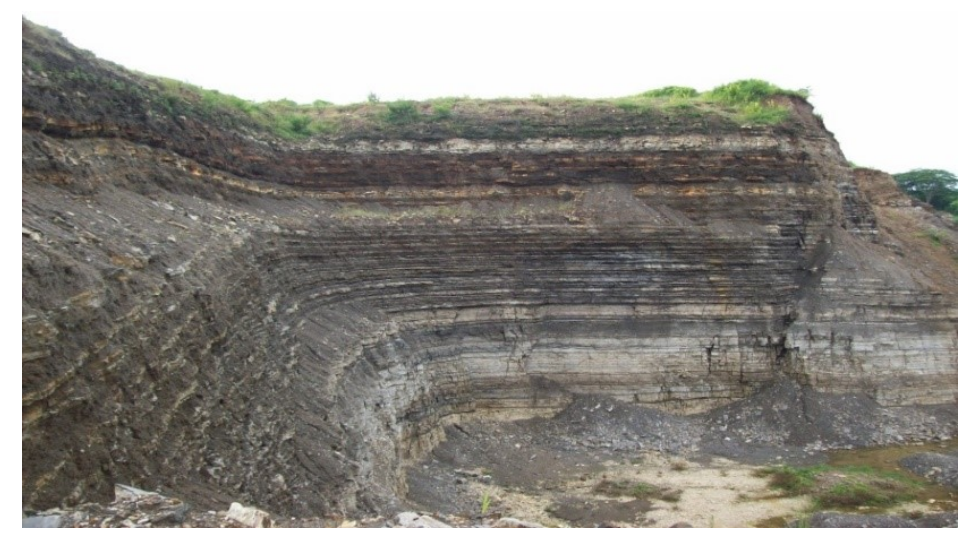

Figura 3: Mineradora no município de Perolândia/GO. Presença de rochas calcárias, folhelhos e basaltos.

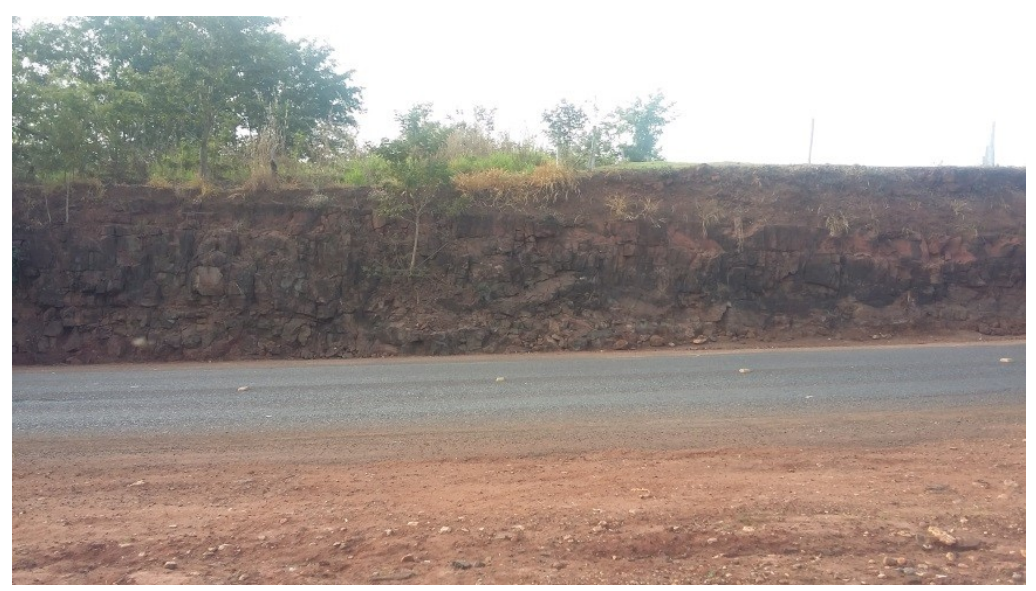

Figura 4: Próximo a ponte do Rio Claro em Caçu/GO. Presença de rochas basaltos. Formação geológica Serra Geral.

Nota-se que a declividade interfere na ocupação do solo, de modo que ao norte da bacia, onde se localizam áreas com declividades mais acentuadas, a preservação do bioma cerrado é mais notada se comparada com áreas mais planas do centro-sul.

Para o tema solos, observa-se, conforme suas respectivas proporções apresentadas na Tabela 2, que a bacia em estudo apresenta os seguintes tipos de solos: Latossolos, Argissolos, Cambissolos, Gleissolos, e Neossolos, respectivamente do solo mais resistente ao menos resistente. A vulnerabilidade para este tema, e refere-se a capacidade de determinado solo resistir a erosão hídrica, dada suas características naturais de morfogênese e pedogênese.

Com maior representatividade na área em estudo, os Latossolos $(64,1 \%)$ são muito utilizados para agricultura, em geral, muito intemperizados, profundos e de boa drenagem. Sua fertilidade natural é baixa, o que exige constantes processos de correções de solos. Este tipo de solo também tende a se compactar com facilidade, sendo a presença ascendente de máquinas no campo um agravante a esta situação, o que infere dizer que devem ser monitorados com regularidade para minimizar os efeitos da degradação ambiental. Estas áreas são consideradas áreas estáveis, podendo ser observados exemplos nas Figuras 7 e 8.

Os Argissolos (6,9\%) têm como característica marcante um aumento de argila em seus horizontes e, juntamente com os Latossolos, são os solos mais expressivos do Brasil. É importante ressaltar que as áreas cobertas por esse tipo de solo e as demais formações areníticas compostas por sedimentos, necessitam de atenção especial nas atividades agropecuárias por apresentarem maior potencialidade erosiva. Estas áreas são consideradas de estabilidade intermediária. 


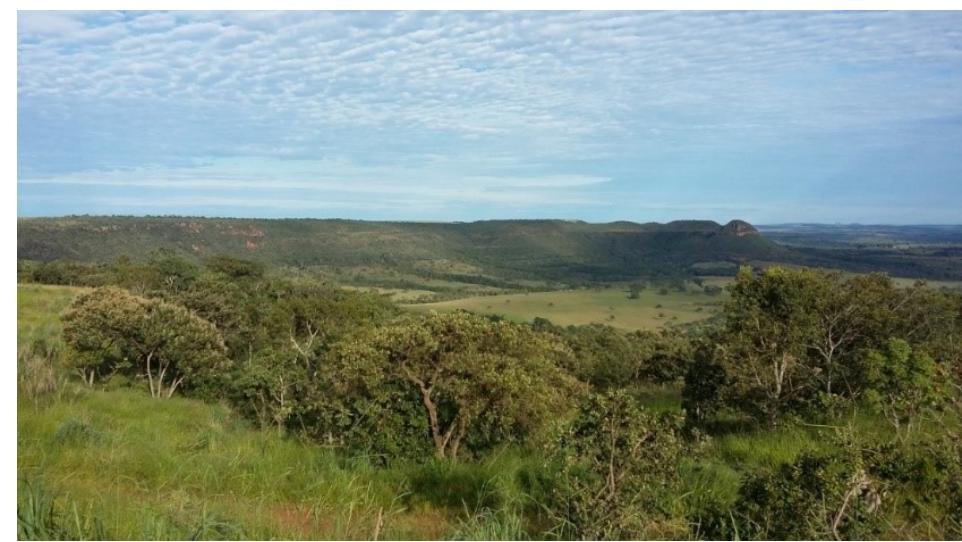

Figura 5: Serra do Caiapó, na divisa dos municípios de Jataí e Caiapônia (GO). Fonte: A autora, 2017.

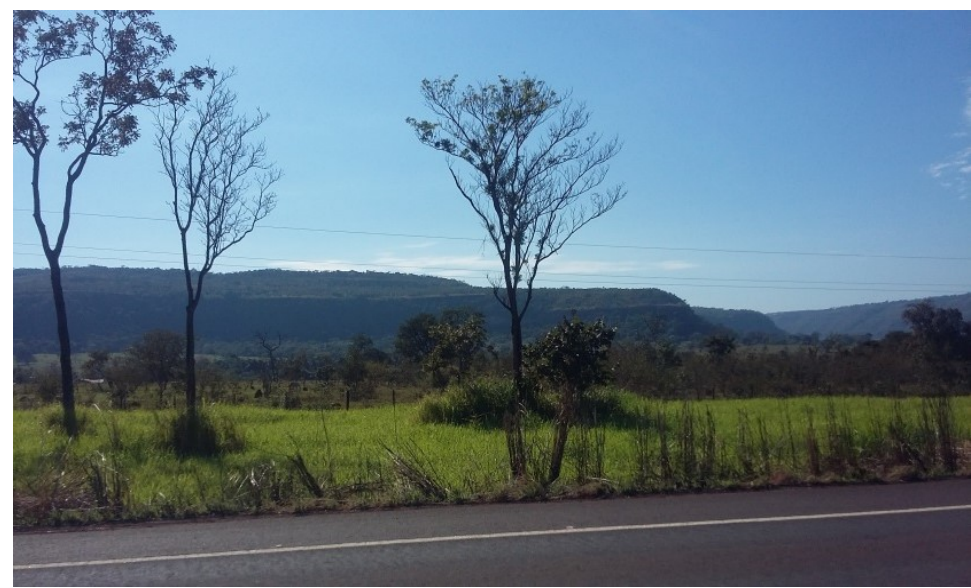

Figura 6: Serra as margens da BR-364 em Cachoeira Alta (GO).

Tabela 2: Escala de Vulnerabilidade à denudação das rochas mais comuns para a Bacia Hidrográfica do Rio

\begin{tabular}{cccc}
\multicolumn{4}{c}{ Claro. } \\
\hline Classificação de Solos (Embrapa, 1999) & $\mathbf{K m}^{\mathbf{2}}$ & $\mathbf{\%}$ & Vuln. \\
\hline Latossolos & 8724,6 & 64,1 & 1,0 \\
Argissolos & 947,5 & 6,9 & 2,0 \\
Cambissolos & 2350,4 & 17,3 & 2,5 \\
Gleissolos & 817,4 & 6,0 & 3,0 \\
Neossolos & 771,1 & 5,7 & 3,0 \\
TOTAL & 13611,0 & 100 & - \\
\hline
\end{tabular}

Fonte: Modificado de Crepani et al., 2001. Florenzano, T. G. (org.), 2008.

Os solos e as formações geológicas dos quais são provenientes também são variáveis de grande importância nesse tipo de análise de ocupação, observa-se que áreas com presença de Argissolos e Latossolos são mais utilizadas para agricultura e pecuária, e isso se justifica pelas condições topográficas em que se apresentam.

Os Cambissolos (17,3\%) são solos que apresentam grande variação de profundidade e drenagem, muitas vezes são pedregosos, cascalhentos e mesmo rochosos o que dificulta sua utilização para fins de agricultura. Estas áreas são consideradas de estabilidade intermediária, tendenciadas a vulnerável, podendo ser observado um exemplo na Figura 9.

Característicos de áreas alagadas ou sujeitas a alagamento, os Gleissolos $(6,0 \%)$ estão estritamente associados às drenagens da BHRC. Estas áreas são consideradas vulneráveis, podendo ser observado um exemplo na Figura 10. Os Neossolos (5,7\%), por sua vez, são constituídos por material mineral ou material orgânico pouco espesso, ocorrem de forma dispersa em ambientes específicos, na área em estudo encontra-se nos relevos muito acidentados de morrarias e serras (Neossolos Litólicos). Estas áreas são consideradas vulneráveis, podendo ser observado um exemplo na Figura 11. 


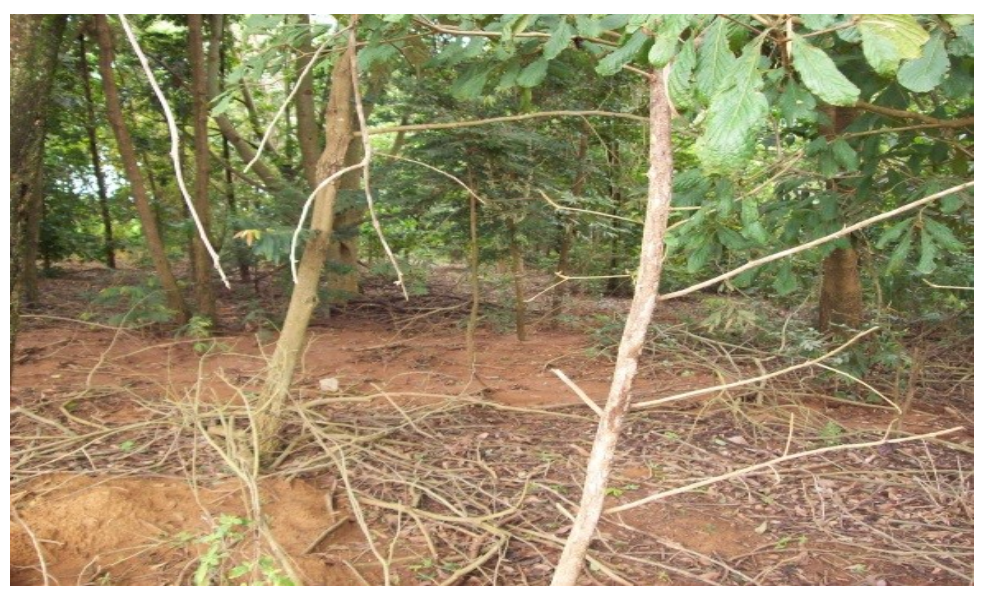

Figura 7: Latossolo Amarelo. Presença de árvores impróprias usadas para reflorestamento.

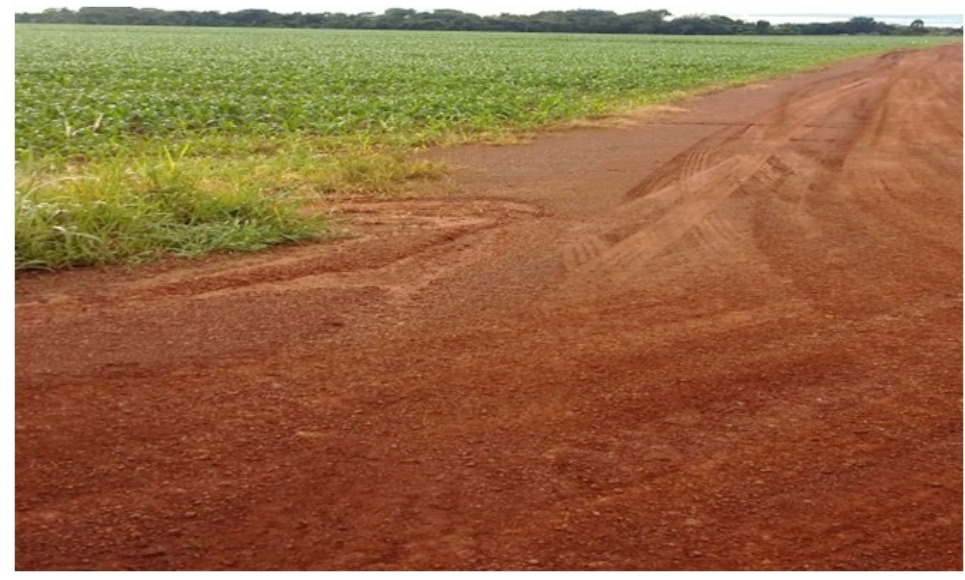

Figura 8: Latossolo Vermelho. Plantação de milho.

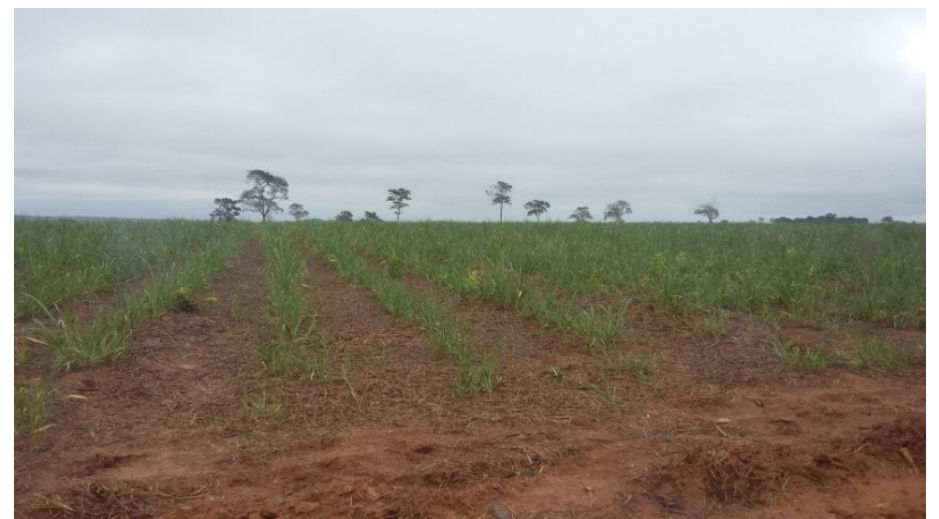

Figura 9: Cambissolo. Bacia do córrego da Onça que deságua no ribeirão Paraíso. Fonte:

A visão sistêmica da bacia nos permite compreender que os processos de degradação e contaminação dos solos estão diretamente relacionados à contaminação dos recursos hídricos, do lençol freático e consequentemente dos mananciais da bacia hidrográfica. Isso também se dá devido à ocupação antrópica da região e seu uso e ocupação para agropecuária. As classes de cobertura vegetal e uso da terra da BHRC podem ser vistas na Tabela 3 .

Os Neossolos $(5,7 \%)$, por sua vez, são constituídos por material mineral ou material orgânico pouco espesso, ocorrem de forma dispersa em ambientes específicos, na área em estudo encontra-se nos relevos muito acidentados de morrarias e serras (Neossolos Litólicos). Estas áreas são consideradas vulneráveis, podendo ser observado um exemplo na Figura 11.

Observou a ocupação antrópica em áreas urbanas $(0,3 \%)$ e o favorecimento de práticas de agricultura $(42,8 \%)$, pecuária $(35,4 \%)$ e silvicultura $(0,4 \%)$. A predominância das atividades agropecuárias é evidente em diversas áreas de cabeceira de drenagem da bacia. Também foram observados pivôs centrais de irrigação em alguns municípios, como em Jataí 


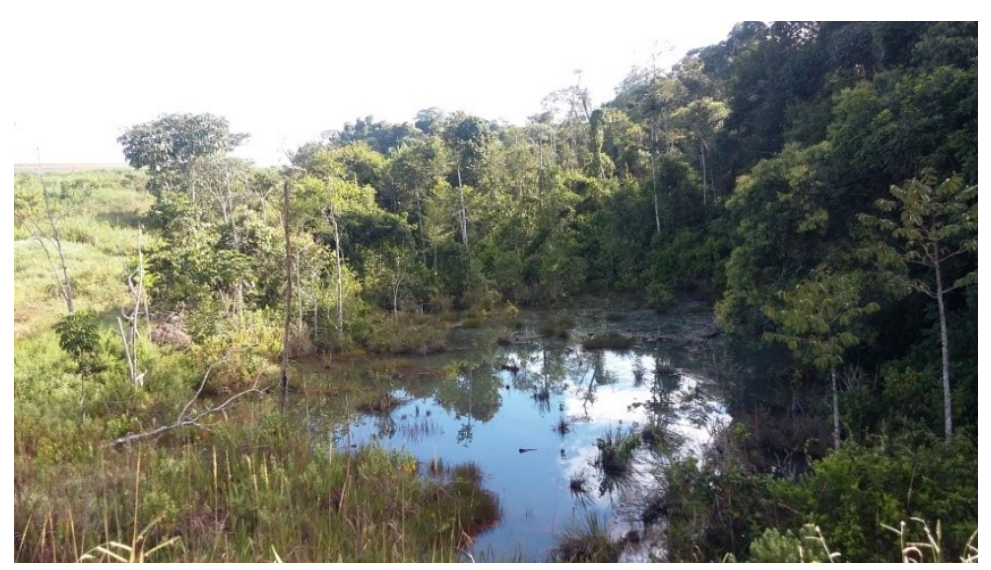

Figura 10: Gleissolo. Solo hidromórfico próximo ao rio Claro. Fonte:

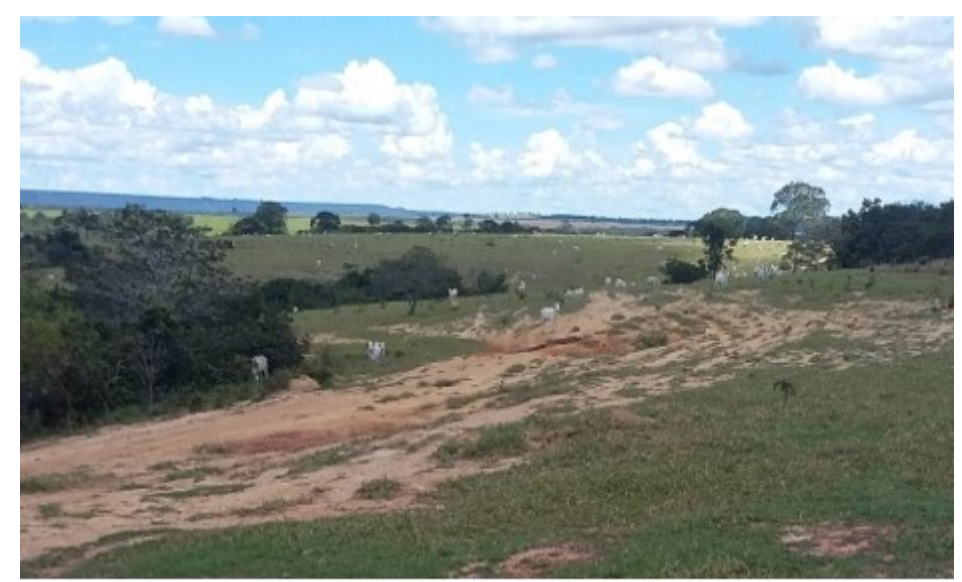

Figura 11: Neossolo. Solo arenoso. Área apresentando pasto e gado nas reservas florestais.

Tabela 3: Classes de cobertura vegetal e uso da terra. Bacia Hidrográfica do Rio Claro na mesorregião Sul Goiano - Goiás - Brasil. 2016.

\begin{tabular}{cccc}
\hline Classes & $\begin{array}{c}\left.\text { Área } \mathbf{( k m}^{\mathbf{2}}\right) \\
\mathbf{2 0 1 6}\end{array}$ & Porc. (\%) & Vuln. \\
\hline Agricultura & 5819,0 & 42,8 & 2,7 \\
Água & 106,7 & 0,8 & 1,0 \\
Área Urbana & 41,5 & 0,3 & 3,0 \\
Silvicultura & 56,2 & 0,4 & 2,7 \\
Pastagem & $4.820,0$ & 35,4 & 3,0 \\
Vegetação Remanescente & 2767,6 & 20,3 & 2,2 \\
Total & 13611,0 & 100,0 & - \\
\hline
\end{tabular}

Fonte: Crepani et al. (1996). Adaptado pela autora, 2017.

Segundo a SEMARH (2011) o uso das águas para abastecimento público é feito principalmente pelas águas de superfície, a partir das UHEs, PCHs CGHs e, de forma complementar, por águas subterrâneas. É importante ressaltar, nesse sentido, que existe a possibilidade de contaminação por agrotóxicos e pesticidas devido às atividades agropecuárias próximas aos pontos de captação de água. Isso representa um risco eminente à população que consome dessa água ou a utiliza para dessedentação de animais. Outo fato a ser considerado é que em função da deficiência dos projetos de saneamento básico, em alguns pontos da BHRC, efluentes sanitários são lançados, sem tratamento, nos cursos d'água.

Observa-se um potencial avanço da silvicultura $(0,4 \%)$ na região. Tal atividade envolve muitos profissionais e vem se mostrando como alternativa para os produtores diversificarem suas produções e melhorarem sua renda.

As modificações antrópicas observadas afetam os ecossistemas devido à modificação do habitat fluvial e terrestre, principalmente pelas existências de barramentos e pela diminuição gradativa de áreas de vegetação remanescente. As áreas de vegetação remanescente representam 20,3\% da BHRC, mas pôde-se 
observar que tais áreas são, em sua maioria, áreas de proteção obrigatória previstas em lei, como as reservas legais e as APPs, e que de vegetação nativa do bioma Cerrado, apenas restam poucos exemplares que estão localizados em áreas com declividade acentuada e de difícil mecanização, ou em solos menos produtivos ao plantio.

Os valores de vulnerabilidade para o uso da terra, segundo Crepani et al. (1996), foram atribuídos levando em consideração que as áreas urbanas e pastagens, devido as ações antrópicas, são mais vulneráveis, assim como as áreas de agricultura e silvicultura. Estas duas últimas classes receberam um peso menor, pois, em relação às primeiras, conservam maior densidade de cobertura vegetal. As áreas com vegetação remanescente foram consideradas intermediárias, com tendência a vulnerabilidade. As áreas de massa d'água, em relação às demais classes, foram consideradas com menor vulnerabilidade.

Para o tema Clima, observou-se que a precipitação total na BHRC, de acordo com a série histórica de 1985 a 2016, apresentou média de aproximadamente 1400,00 mm, e que a intensidade pluviométrica (IP) variou de 421,00 mm/mês a 480,90 mm/mês, conforme Tabela 4 .

As áreas mais próximas das nascentes dos principais canais fluviais da bacia, e consequentemente, de maiores altitudes, apresentaram maior IP, e menor grau de vulnerabilidade à perda de solo das unidades de paisagem. O grau de vulnerabilidade do clima (o qual é dado em relação a IP) dentro da BHRC variou de 2,4 a 2,6, (Tabela 5), sendo considerado vulnerável.

A BHRC, considerando os elementos e fatores climáticos e a circulação geral da atmosfera, é classificada como de Clima Tropical, o qual apresenta elevada temperatura durante todo o ano e baixa amplitude térmica.

A altitude e a configuração do relevo são fatores que interferem na questão climática, sendo que a medida que a altitude aumenta, há um decréscimo na temperatura. Os municípios com altitudes mais elevadas são Perolândia, Caiapônia, Rio Verde e Jataí, locais esses onde se encontram as nascentes dos principais rios da BHRC. Devido à baixa temperatura nesses municípios ocasionalmente podem ocorrer geadas, eventos esses pontuais, mas que prejudicam áreas de lavoura.

A precipitação pode ser considerada elevada. O tipo mais comum é o de chuva convectiva no qual forma-se por forte evaporação, seguida de condensação e de precipitação a qual é medida em milímetros $(\mathrm{mm})$. A pluviometria caracteriza a existência de dos períodos distintos na BHRC, sendo um período de seca com duração entre maio a setembro, e um período úmido entre outubro a abril.

A análise de vulnerabilidade do clima é importante para caracterizar os processos erosivos na BHRC, dado que associadas a fatores como o afloramento rochoso, a espessura do solo e inexistência de cobertura vegetal densa, a intensidade pluviométrica alerta quanto a distribuições das chuvas e a possibilidade de haverem eventos torrenciais que transportem o solo.

Foram gerados os mapas de vulnerabilidade para os cinco temas propostos (Geologia, Geomorfologia, Solos, Vegetação/Uso da terra e Clima), conforme podem ser observadas nas Figuras $\mathbf{1 3}$ a 17, respectivamente

Por fim, foi elaborado o mapa de vulnerabilidade à perda de solo das unidades de paisagem usando a média dos cinco temas propostos pela metodologia de Crepani (2001), conforme Figura 18. Observou-se que a área estudada apresenta $19,9 \%\left(2701,8 \mathrm{~km}^{2}\right)$ de áreas classificadas como de maior vulnerabilidade (considerando a escala de Vuln. entre 2,9 e 2,5) e se concentram mais nos interflúvios das principais drenagens da bacia e nas áreas de serras.

Apresenta 44,1\% $\left(5981,7 \mathrm{~km}^{2}\right)$ de áreas de estabilidade intermediária, tendenciadas a vulnerável (considerando a escala de Vuln. entre 2,4 e 2,1). As áreas estáveis, mas com tendência a vulnerável, são importantes para conservação na BHRC e estão localizadas principalmente próximas as principais nascentes da BHRC onde houve supressão da cobertura vegetal natural pra implantação das lavouras. Observou-se uma tendência à ampliação das áreas de Agricultura na região o que irá representar, por consequência, uma ampliação dessas áreas vulneráveis.

Apresenta 34,6\% $\left(4705,8 \mathrm{~km}^{2}\right)$ de áreas de estabilidade intermediária, tendenciadas a estável (considerando a escala de Vuln. entre 2,0 e 1,6). Apresenta 1,6\% $\left(221,7 \mathrm{~km}^{2}\right)$ de áreas de maior estabilidade (considerando a escala de Vuln. entre 1,5 e 1,3).

Em campo observou-se uma vulnerabilidade maior do que a que foi apresentado nos resultados dos Mapas. Isso se deve pela vulnerabilidade obtida em alguns temas como o clima, que não pôde ser analisado com maior precisão devido às distâncias entre as estações meteorológicas e a falta de dados nas séries históricas, e o tema geomorfologia cuja vulnerabilidade foi baixa devido a BHRC ter em sua área maior 
quantidade de terrenos planos. A metodologia de Crepani, 2001, considera pesos iguais para as variáveis, enquanto que para a conservação o ideal é que o uso tivesse um peso maior.

Tabela 4: Escala de erosividade da chuva e valores de vulnerabilidade relativos á perda de solo para a Bacia Hidrográfica do Rio Claro.

\begin{tabular}{cccccccc}
\hline $\begin{array}{c}\text { Estações } \\
\text { Meteorológicas }\end{array}$ & UF & Lat. & Long. & $\begin{array}{c}\text { Prec. } \\
\text { Total }\end{array}$ & DPC* & IP** & Vuln. \\
\hline Aragarças & GO & $-15,90$ & $-52,23$ & 1405,10 & 2,9 & 480,90 & 2,8 \\
Capinópolis & MG & $-18,71$ & $-49,55$ & 1411,99 & 3,2 & 435,62 & 2,6 \\
Itarumã & GO & $-18,71$ & $-51,35$ & 1244,27 & 2,7 & 455,22 & 2,7 \\
Ituiutaba & GO & $-18,41$ & $-49,21$ & 1348,44 & 3,0 & 454,85 & 2,7 \\
Jataí & GO & $-17,91$ & $-51,71$ & 1610,80 & 3,8 & 421,00 & 2,5 \\
Paranaíba & MS & $-19,75$ & $-51,18$ & 1358,67 & 3,1 & 438,28 & 2,6 \\
Pombal & GO & $-18,10$ & $-51,50$ & 1501,15 & 3,4 & 443,42 & 2,7 \\
Poxoreo & MT & $-15,83$ & $-54,38$ & 1677,79 & 3,5 & 478,41 & 2,8 \\
Rio Verde & GO & $-17,8$ & $-50,91$ & 1523,39 & 3,7 & 415,28 & 2,5 \\
Rondonópolis & MT & $-16,45$ & $-54,56$ & 1162,29 & 3,1 & 374,7 & 2,3 \\
\hline & *Duração do período chuvoso = quantidade de meses com registro de precipitação pela estação meteorológica. \\
Média da séria histórica de 1985 a 2016.**Intensidade pluviométrica = (pluviosidade anual/ duração do período \\
chuvoso).Fonte: BDMEP - INMET, 2016. ANA, 2016. Crepani et al. (1996). Adaptado pelos autores. \\
\hline
\end{tabular}

Tabela 5: Escala de erosividade da chuva e valores de vulnerabilidade á perda de solo.

\begin{tabular}{cccc}
\hline $\begin{array}{c}\text { Intensidade } \\
\text { Pluviométrica }-\mathbf{I P} \\
(\mathbf{m m} / \mathbf{m e ̂ s})\end{array}$ & $\begin{array}{c}\text { Área } \\
\left.\mathbf{( k m}^{\mathbf{2}}\right)\end{array}$ & Porcentagem (\%) & $\begin{array}{c}\text { Vulnerabilidade- } \\
\text { Vuln. }\end{array}$ \\
\hline $375-400$ & 725,8 & 5,3 & 2,4 \\
$400-425$ & 39,2 & 0,28 & 2,5 \\
$425-450$ & 12845,9 & 94,4 & 2,6 \\
Total & 13611,0 & 100,0 & - \\
\hline & Fonte: Fonte: Crepani et al. (1996). Adaptado pela autora, 2017.
\end{tabular}

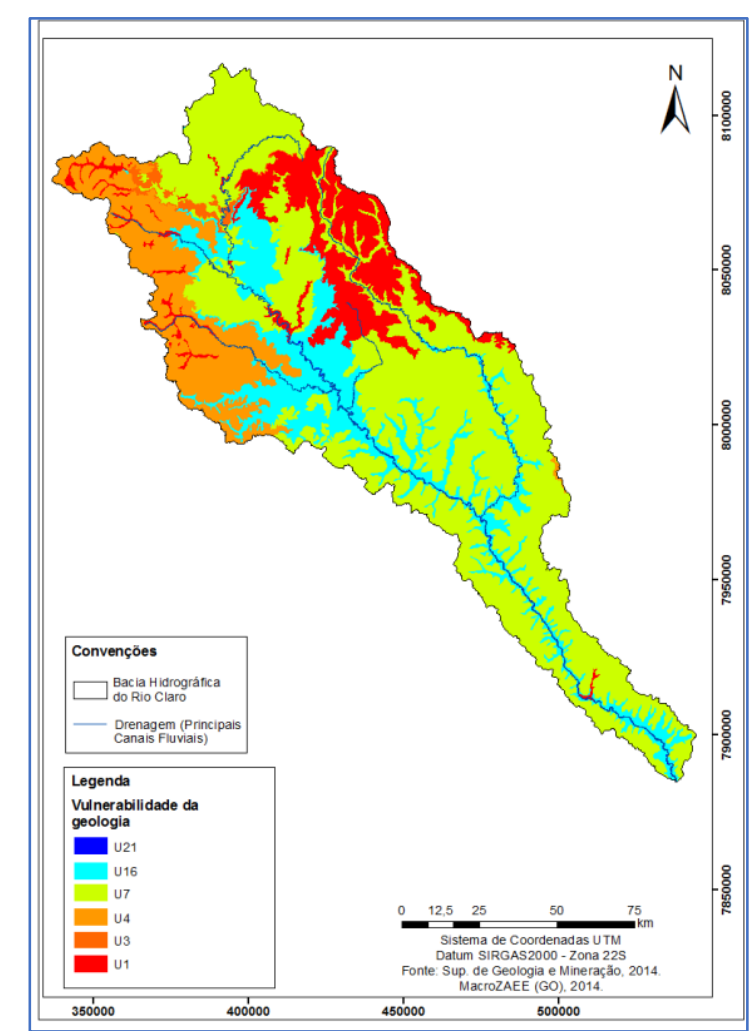

Figura 13: Vulnerabilidade da Geologia. Bacia Hidrográfica do Rio Claro na mesorregião Sul Goiano Goiás - Brasil. 


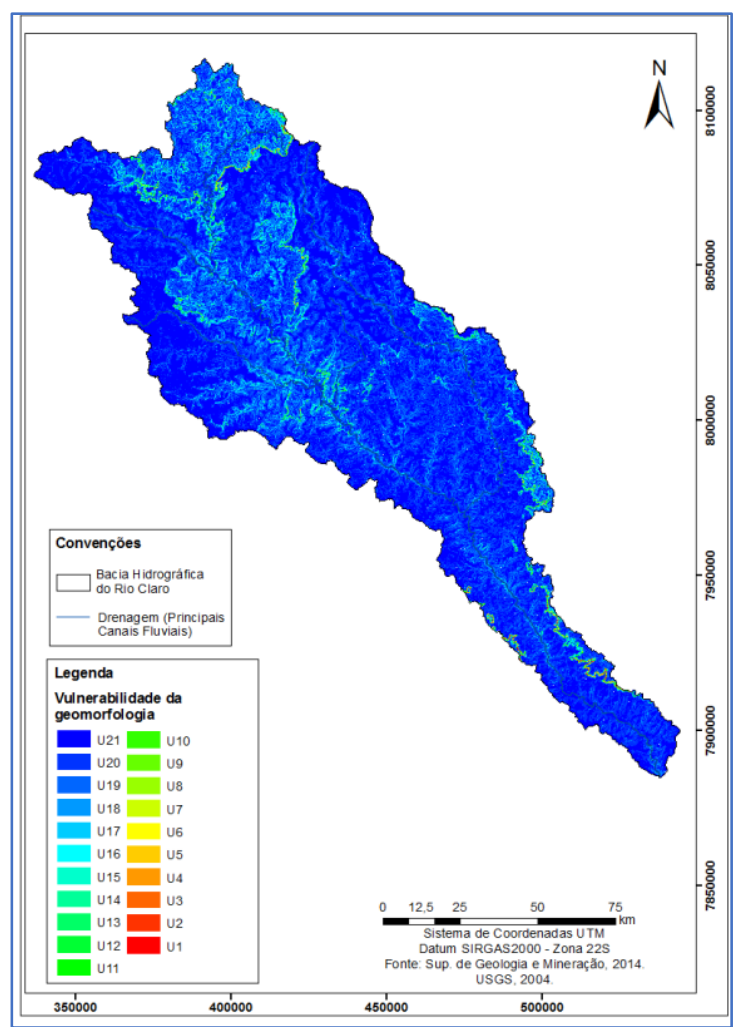

Figura 14: Vulnerabilidade da Geomorfologia. Bacia Hidrográfica do Rio Claro na mesorregião Sul Goiano - Goiás - Brasil.

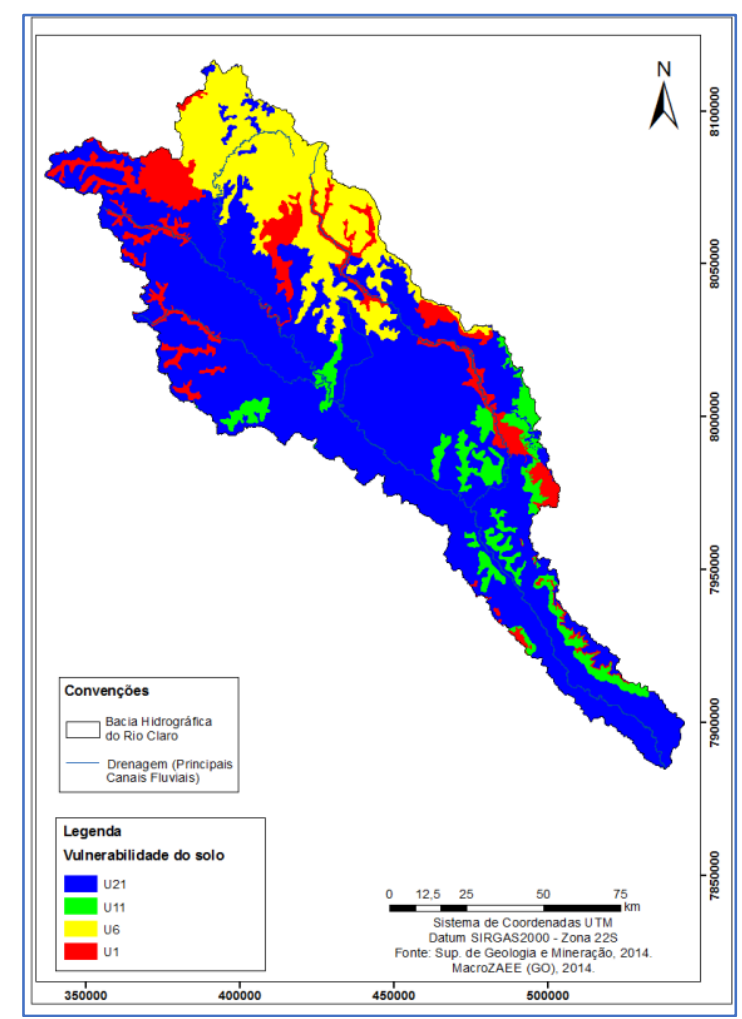

Figura 15: Vulnerabilidade do Solo. Bacia Hidrográfica do Rio Claro na mesorregião Sul Goiano Goiás - Brasil. 


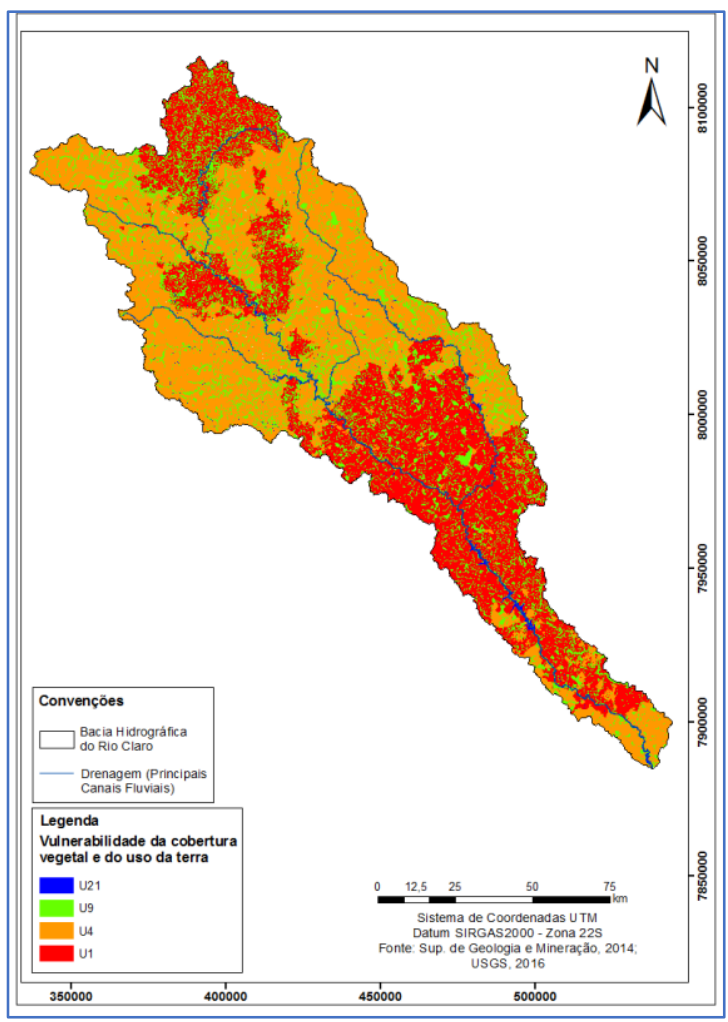

Figura 16: Vulnerabilidade da cobertura vegetal do uso do solo. Bacia Hidrográfica do Rio Claro na mesorregião Sul Goiano - Goiás - Brasil.

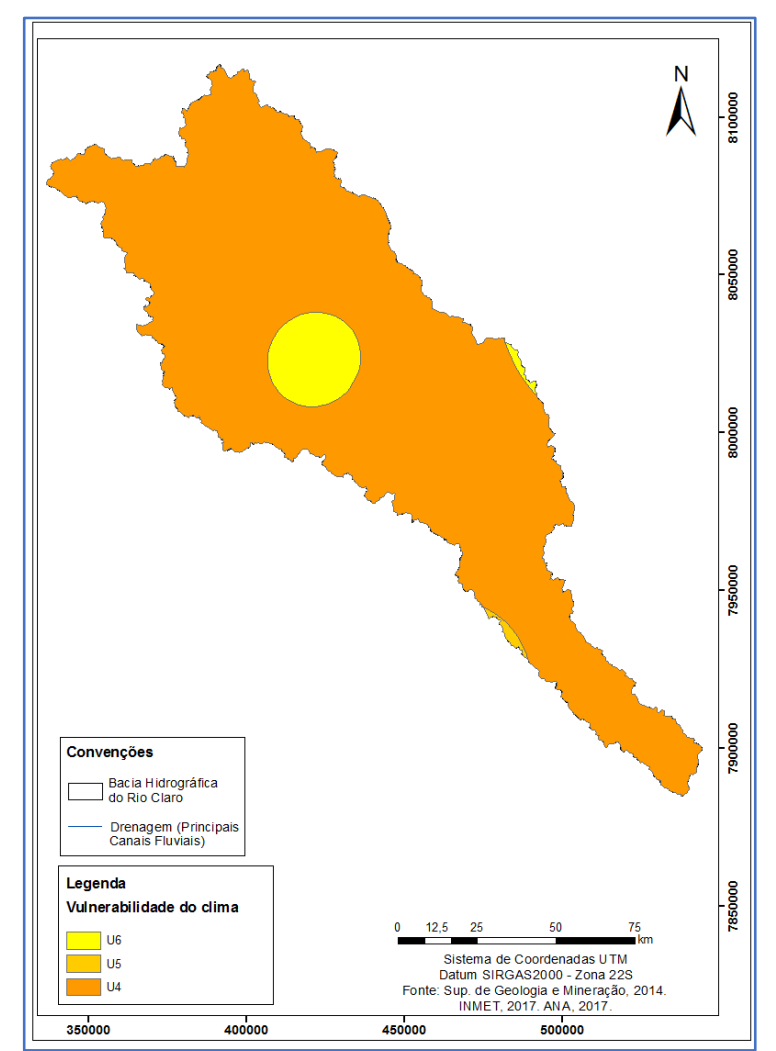

Figura 17: Vulnerabilidade do Clima. Bacia Hidrográfica do Rio Claro na mesorregião Sul Goiano Goiás - Brasil. 


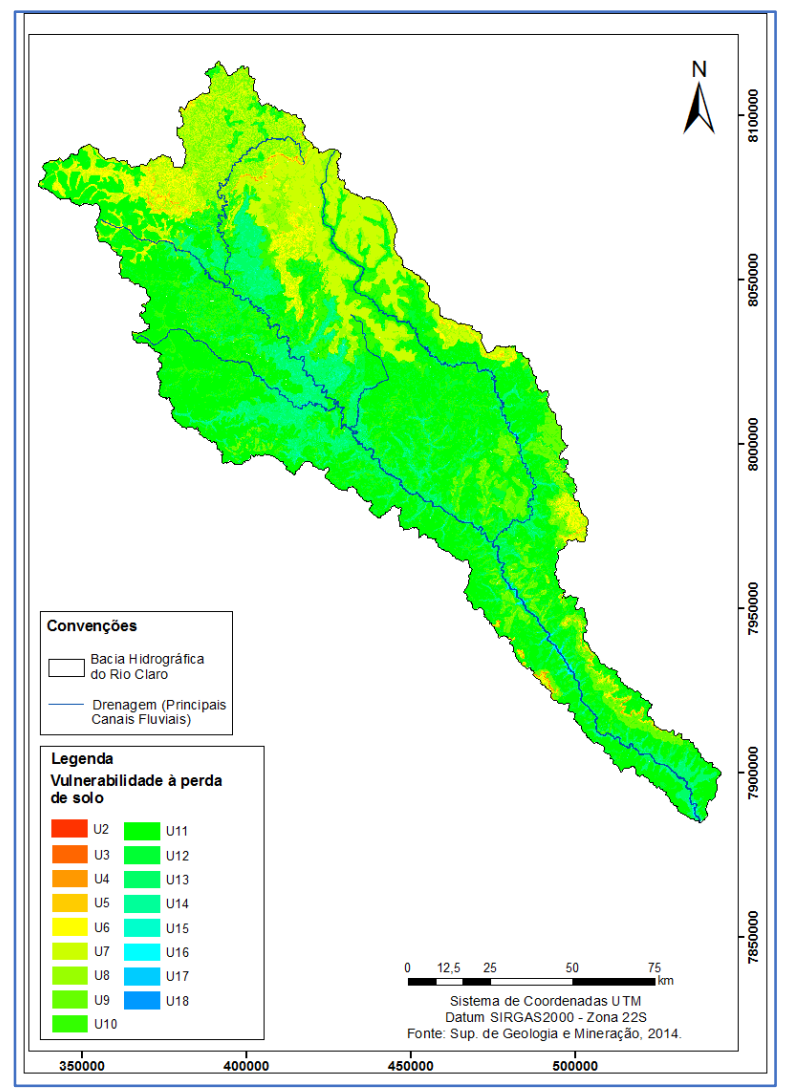

Figura 18: Vulnerabilidade à perda de solo das unidades de paisagem. Bacia Hidrográfica do Rio Claro na mesorregião Sul Goiano - Goiás - Brasil.

\section{Considerações finais}

Conclui-se que a aplicação da teoria de sistemas e as técnicas de geoprocessamento mostraram-se eficientes para viabilizar o cumprimento dos objetivos aqui propostos. As mesmas orientaram a determinação da vulnerabilidade dos ambientes naturais na BHRC caracterizando-a como de estabilidade intermediária, tendenciada a vulnerável. Tal resultado pôde ser comprovado dados os aspectos de degradação dos recursos hídricos mapeados e validados em campo.

O uso da terra para fins agropecuários, bem como sua caracterização quanto a geologia e relevo, possibilitou observar o grande potencial da região para tais atividades, bem como os riscos de degradação que tal uso pode gerar se não forem praticadas técnicas adequadas de manejo. Observou-se que as áreas mais vulneráveis na BHRC encontram-se próximas as suas principais nascentes, tal dado indica a necessidade de intensificação de ações de conservação nessas áreas.

O presente trabalho alerta quanto à necessidade de se intensificarem políticas específicas para controle e monitoramento ambiental, visando à recuperação e manutenção dos recursos hídricos a fim de assegurar que amostras significativas dos biomas e ecossistemas do território nacional sejam utilizadas de forma sustentável e que sejam preservadas. Nesse sentido, se faz necessário associar os dados do meio físico com os dados de potencialidade social e econômica para a elaboração de políticas de gestão territorial

\section{REFERÊNCIAS}

AGUIAR, R.D., SANTOS, L.F.M., MATRICARDI, E.A.T., BATISTA, I.X. Zoneamento de risco de incêndios florestais no Parque Nacional da Chapada dos Veadeiros - GO. Enciclopédia da Biosfera, v. 11, n. 21, p. 19431957, 2015.

BOTELHO, R. G. M., SILVA, A. S. Bacia hidrográfica e qualidade ambiental. In: VITTE, A. C., GUERRA, A. J. T. (organizadores). Reflexões sobre a geografia física no Brasil. 6 ed. Rio de Janeiro: Bertrand Brasil, 2012. $282 \mathrm{p}$. 
CAMPOS, H. L. Gestão de bacia hidrográfica: pressupostos básicos. In: SÁ, A. J.; CORRÊA, A. C. B. Regionalização e analise regional: perspectivas e abordagens contemporâneas. Recife: Editora Universitária, 2006. p. 91-111.

CHRISTOFOLETTI, A.. Modelagem de sistemas ambientais. $1^{\text {a }}$ edição. São Paulo: Edgard Blücher, 1999.

CHRISTOFOLETTI, A. Geomorfologia. 2 ed, São Paulo: Blucher, 1980.

COHEN, J. A coeficient of agreement for nominals scales., v.20, n.1. Washington: Journal of Educational and Measurement, 1960. p.37-46.

COIMBRA, P. J., TUBÚRCIO, J. A. M. Geografia: uma análise do espaço geográfico. 3 ed. São Paulo: HARBRA, 2006.

CREPANI, E. et al. Zoneamento Ecológico-Econômico. In: FLORENZANO, T. G (Org.). Geomorfologia: conceitos e tecnologias atuais. São Paulo: Oficina de textos, 2008. p.318.

CREPANI, E. et al. Curso de sensoriamento remoto aplicado ao zoneamento ecológico-econômico. In: Simpósio Brasileiro de Sensoriamento Remoto, 8., Salvador, 1996. Anais... São Paulo: Image Multimídia, 1996. Seção de Comunicações Técnico-científicas. CD-ROM.

CREPANI, E. et al. Sensoriamento remoto e geoprocessamento aplicados ao zoneamento ecológicoeconômico e ao ordenamento territorial. São José dos Campos: Inpe, jun. 2001. INPE-8454-RPQ/722.

ESRI - Environmental Systems Research Institute Inc. ArcGis versão 9.3. EUA: Environmental Systems Research Institute, 2008.

FLORENZANO, T. G (Org.). Geomorfologia: conceitos e tecnologias atuais. São Paulo: Oficina de textos, 2008. P.318.

MAGNOLI, D. Projeto de ensino de geografia: natureza, tecnologias, sociedades, geografia geral. 2 ed. São Paulo: Moderna, 2004.

MARTINS, A. P. et al. Uso da terra e cobertura vegetal de 1985 a 2015 no sudoeste de Goiás e relações com o meio físico. In: PEIXINHO, D. M., SOUSA, M. S. Reconfigurações do Cerrado: Uso, Conflitos, e Impactos Ambientais. Goiânia: Gráfica UFG, 2016. 268 p.

MOREIRA, R. O pensamento geográfico brasileiro. vol. 1: as matrizes clássicas. $2^{\mathrm{a}}$ ed., $2^{\mathrm{a}}$ reimpressão. São Paulo: Contexto, 2014.

NOVO, E. M. L. de M. Ambientes Fluviais. In: FLORENZANO, Teresa Gallotti (org.). Geomorfologia: conceitos e tecnologias atuais. São Paulo: Oficina de textos, 2008.

QUEIROZ, G. J. de F. Modernização agrícola e transformações socioespaciais em Goiás: desigualdades e concentração no desenvolvimento regional no período de 1930 a 2007. 2010. 278 f. (Tese de doutorado na área de Geografia e gestão do território) - Universidade Federal de Uberlândia. 2010.

RODRIGUES, C. A teoria Geossistêmica e sua contribuição aos estudos GeoGráficos e Ambientais. Revista do Departamento de Geografia, v. 14 (2001), p. 69-77.

RodrigueZ, J. M. M., SILVA, E. V., CAVAlCANTE, A. P. B. Geoecologia das Paisagens: uma visão geossistêmica da análise ambiental. 5 ed Fortaleza: Edições UFC, 2017. 222 p.

ROSS, J. L. S. Análise empírica da fragilidade dos ambientes naturais e antropizados. Revista do Departamento de Geografia da USP, São Paulo, SP. n. 8, p. 63-74, fev. 1993.

SALES, V. C. Geografia, sistemas e análise ambiental: abordagem crítica. GEOUSP - Espaço e Tempo, São Paulo, No 16, pp. 125 - 141, 2004.

SANTOS, M. Espaço e método. São Paulo: Nobel, 1985.

SECIMA - Secretaria do Meio Ambiente, dos Recursos Hídricos, Infraestrutura, Cidades e Assuntos Metropolitanos. Afluentes goianos do baixo Paranaíba.

SIEG - Sistema Estadual de Estatística e Informações Geográficas de Goiás. Base cartográfica e Mapas temáticos do Estado de Goiás.

SILVA, A. S. da. Bacia hidrográfica e qualidade ambiental. In: VITTE, Antônio Carlos; GUERRA, Antônio José Teixeira (org.). Reflexões sobre geografia física no Brasil. 6 ed. Rio de Janeiro: Bertrand Brasil, 2012.

STEFAN, L., BLASCHKE, T. Trad. Hermann Kux. Análise da paisagem com SIG. São Paulo: Oficina de Textos, 2009.

TRICART, J. Ecodinâmica. Rio de Janeiro: FIBGE: Supren, 1977. 